\title{
Patterns and determinants of acute psychiatric readmissions
}

\author{
Graham Michael Behr, MB BCh, FCPsych (SA) (Current \\ affiliation: Department of Psychiatry, St Mary's Hospital, \\ London)
}

Cathy Christie, MB BCh, FCPsych (SA)

Department of Psychiatry, University of the Witwatersrand, Johannesburg

Neil Soderlund, MB BCh, MSC, DPhil

Tennyson Lee, MB BCh, FFCH (SA) (Current affiliation: Department of Psychiatry, Maudsley Hospital, London) Centre for Health Policy, University of the Witwatersrand, Johannesburg

Objectives. Deinstitutionalisation and shortage of psychiatric beds worldwide has led to extensive research into the risk factors and interventions associated with rapid and recurrent admission to hospital. Little research of this nature has taken place in South Africa, particularly with regard to acute hospital admissions. This study attempted primarily to assess the effect of length of stay and administration of depot antipsychotics in hospital on time to readmission.

Design. A retrospective cohort of 180 admissions was followed up for 12 months, after an index discharge, by means of multiple hospital and community-based record reviews. Each readmission was analysed as an event using a survival analysis model.

Setting. Chris Hani Baragwanath Hospital, Gauteng.

Subjects. A random sample of patients admitted during a 6-month period in 1996.

Outcome measures. Time to readmission.

Results. Two hundred and eighty-four admissions were analysed. The only factor that provided a significant protective effect was being married or cohabiting (P=0.015). Clinic attendance showed a slight protective effect early on but con- ferred a significantly higher risk of readmission on those who had been out of hospital for a long period $(P=0.001)$. Only $21 \%$ of discharged patients ever attended a clinic. The overall risk of readmission was significantly higher in the first 90 days post discharge.

Conclusions. The lack of impact of length of hospital stay and use of depot neuroleptics on time to readmission may indicate that patients are being kept for appropriate duration and that the most ill patients are receiving depot medication.

Several sampling and statistical artefacts may explain some of our findings. These results confirm the worldwide difficulty in finding consistent and accurate predictors of readmission. Low rates of successful referral to community aftercare need to be addressed before their effectiveness can be reasonably assessed. The inherent instability of the post-discharge period is a potential area for further investigation and intensive management.

S Afr MedJ 2002; 92: 369-374.

International trends have seen a policy shift from chronic psychiatric institutions and long hospital admissions towards acute, short hospital stays and community-based care. Following this process a dramatic increase in relapse rates has been noted among a particular subgroup of psychiatric patients. The general decline in number of hospital beds and mental hospital population size seems to have directly paralleled the increasing rate of readmissions for certain patients.'

The pressure on psychiatric beds has prompted much research on the variables associated with relapse, particularly those linked to rapid relapse. Studies of factors associated with multiple or rapid readmission in psychiatric patients have included demographic factors, illness-related variables and variables related to aftercare and quality of life. 
The demographic factors associated with poor outcome include young age, ${ }^{25}$ male gender, ${ }^{1,2,46}$ marital status (single or divorced), ${ }^{2}$ low educational level, ${ }^{7}$ unemployment ${ }^{6}$ and living in large urban environments. ${ }^{8,9}$

Illness-related variables include diagnosis, illness severity, length of hospital stay and previous admissions. Schizophrenia, bipolar mood disorder, schizoaffective disorder and co-morbid substance abuse patients are identified as diagnostic risk groups. ${ }^{13,9}$ Severity of illness at discharge, ${ }^{10,11}$ early age of illness onset, ${ }^{1}$ duration of illness, ${ }^{12}$ multiple previous admissions ${ }^{11,13}$ and violent behaviour have also been noted as predictors of multiple and early relapse.

Because of the pressure to discharge patients prematurely, a number of investigators have asked whether early discharge and short hospital stays are predictors of early relapse. Although three studies $^{1,4,14}$ reviewed supported this notion, three others did not. ${ }^{10,15,16}$ The influence of length of hospital stay on relapse rates remains a disputed area.

With regard to aftercare variables, poor treatment compliance was found to predict relapse, 9,13,17 but one study found that use of outpatient services, number of clinic visits and access to care were not significant factors.

Quality of life indicators seem poorly predictive of the 'revolving door' syndrome. ${ }^{9}$ In this category family criticism of the patient ${ }^{9}$ and unsatisfactory family relations ${ }^{11,16}$ are the only variables that have been associated with high relapse rates.

Finally, it has been suggested that the inconsistent and contradictory findings in much of the research may be accounted for by variables that are significant only when they interact with other variables, for example employment and age with living status. ${ }^{10}$

The above studies ${ }^{17}$ were done in developed countries and a review of the literature in Medline over the last 10 years reveals a paucity of research on risk factors for rapid readmissions in developing countries.

\section{Context}

This study was conducted at the Chris Hani Baragwanath Hospital, which has the only acute psychiatric unit in Soweto, South Africa. It has 155 beds, serving a large catchment area of several million people mainly living in conditions of social deprivation.

Because of the shortage of beds our clinical impression was one of patients being prematurely discharged and rapidly readmitted. The aim of the research, therefore, was to identify risk factors for rapid readmission. We looked at a wide array of variables thought to influence this risk and specifically hypothesised that longer length of stay and administration of depot antipsychotics in hospital would increase the time to readmission.

\section{Methods}

The study is both descriptive and analytical. A retrospective cohort of 180 acute admission patients were randomly selected from a total of 952 admissions between 1 February and 31 July 1996. Data collection involved reviews of our hospital records, those of the Soweto community clinics and the only other hospitals likely to have admitted Soweto residents, Sterkfontein and Tara hospitals.

Diagnosis was made by reviewing the case notes using Diagnostic and Statistical Manual of Mental Disorders (DSM IV) criteria. ${ }^{18}$ Occasionally diagnosis was not stable for sequential admissions, and if more than one diagnosis was present in the data, a consultant psychiatrist reviewed the clinical notes and assigned the most likely diagnosis.

Use of community clinics was assessed by review of community clinic files and recorded as the proportion of expected monthly visits where attendance actually occurred. Attendance was assessed from 6 months before the index admission date.

Substance abuse involving cannabis and alcohol was assessed as being a factor on the basis of either biochemical evidence or reports by at least two clinicians. Violence was assessed as being a factor if a specific description of the violent behaviour was present in the records.

We have treated each time frame following an admission as an observation period and measured the time from that discharge until the next readmission, or until follow-up ceased, whichever was sooner.

Each patient was followed up for 1 year after the index discharge regardless of whether or not readmission occurred. The conventional approach to analysing such data in a multivariate fashion is using survival models. The simplest approach to such modelling is to use the Cox proportional hazards model ${ }^{19}$ which assumes that for any risk factor, in this case readmission, the relative hazard is constant over time. Proportional hazards models are obviously unsuited where the hazard attributable to a given factor changes with time. The proportional hazards model can be simply modified to reflect hazards that change in relation to time by incorporating interaction terms between a time-dependent covariate and 
independent variables. We have estimated proportional hazard models for the independent variables using time until readmission or loss to follow-up as the dependent variable, with and without the use of a higher order time-dependent covariant. Both the full model and a reduced-form model determined by forward stepwise selection were used. In the latter case, a partial P-value < 0.05 was required for initial inclusion of a variable in the model, and $a P>0.1$ was required for exclusion from the final model (both estimated using likelihood ratio tests). Maximum likelihood estimators were used in all cases.

\section{Results}

Descriptive statistics for the patients and admissions studied are given in Tables I and II. A total of 180 individuals were followed up for 365 days from their first discharge from hospital. During this time there were 284 admissions for psychiatric illness, giving an average admission rate (including the index admission) of 1.58 in the study period. While the analyses forming the basis of this paper have been done at the level of the admission, rather than the person, many of the explanatory variables will have remained constant for an individual across multiple admissions.

Descriptive statistics are therefore presented separately for characteristics unique to the individual (Table I) and the admission (Table II).

To summarise the personal characteristics: the typical patient followed up was male, single, between 20 and 30 years old, poorly educated, and suffering from schizophrenia or bipolar mood disorder. While most patients were unemployed, few were receiving disability support grants. Approximately one-third had a history of substance abuse and one-quarter a history of violent behaviour preceding admission. Almost two-thirds of patients were not readmitted to hospital during the 1-year follow-up period after the index admission.

Just over half of the patients admitted for psychosis were given depot neuroleptic medication before discharge. Length of stay averaged 37 days for all admissions, and diagnosis was a significant predictor of length of stay overall (one-way analysis of variance (ANOVA), $P=0.02)$. Parasuicide cases had a significantly shorter length of stay than the population average $\mid P<$ 0.05). Schizophrenia and bipolar cases also had much higher variance in length of stay (coefficient of variation $=1.34$ and 1.46 respectively), reflecting the fact that a few cases had very long lengths of stay. Levels of treatment in the community were low, with only $21 \%$ of cases discharged attending their communi-

\begin{tabular}{|c|c|c|}
\hline & $\mathrm{N}$ & $\%$ \\
\hline Total number of patients studied & 180 & \\
\hline Total number of admissions & 284 & \\
\hline \multicolumn{3}{|l|}{ Age category (yrs) } \\
\hline$<21$ & 19 & 10.6 \\
\hline $21-30$ & 71 & 39.4 \\
\hline $31-40$ & 54 & 30.0 \\
\hline $41-50$ & 26 & 14.4 \\
\hline$>50$ & 10 & 5.6 \\
\hline Receiving disability grant & 32 & 17.8 \\
\hline \multicolumn{3}{|l|}{ Diagnosis } \\
\hline Bipolar mood disorder & 41 & 22.8 \\
\hline Major depression & 14 & 7.8 \\
\hline Other psychotic disorder & 18 & 10.0 \\
\hline Parasuicide & 10 & 5.6 \\
\hline Schizophrenia & 69 & 38.3 \\
\hline All other diagnoses & 28 & 15.6 \\
\hline Alcohol dependency & 3 & 1.7 \\
\hline Alcoholic hallucinations & 3 & 1.7 \\
\hline Borderline PD & 3 & 1.7 \\
\hline Cannabis intoxication & 5 & 2.8 \\
\hline Dementia & 1 & 0.6 \\
\hline Mental retardation & 2 & 1.1 \\
\hline Insufficient information & 10 & 5.6 \\
\hline Somatoform disorder & 1 & 0.6 \\
\hline \multicolumn{3}{|l|}{ Highest educational level } \\
\hline Unknown & 24 & 13 \\
\hline Less than Std 8 & 89 & 49 \\
\hline Std 8 or 9 & 51 & 28 \\
\hline Std 10 & 11 & 6 \\
\hline Tertiary qualifications & 5 & 3 \\
\hline Female gender & 64 & 35.6 \\
\hline Married or cohabiting & 52 & 28.9 \\
\hline Employed & 32 & 17.8 \\
\hline History of substance abuse & 64 & 35.6 \\
\hline History of violent behaviour & 47 & 26.1 \\
\hline \multicolumn{3}{|c|}{$\begin{array}{l}\text { Number of readmissions per enrolled } \\
\text { patient }\end{array}$} \\
\hline 0 & 112 & 62.6 \\
\hline 1 & 42 & 23.5 \\
\hline 2 & 16 & 8.9 \\
\hline 3 & 8 & 4.5 \\
\hline$>3$ & 1 & 0.6 \\
\hline $\mathrm{PD}=$ personality disorder. & & \\
\hline
\end{tabular}

ty clinic at all. Of those cases readmitted, 52.9\% had been readmitted within 3 months of discharge, indicating that risk of readmission is significantly higher early after discharge.

In order to analyse the determinants of time until readmission, a Cox proportional hazards regression model was used. Model 1 in Table III shows the results for the proportional hazard of readmission model, with all explanatory variables included. None of the coefficients achieved statistical significance, and the overall 
Table II. Descriptive statistics with regard to admissions

\begin{tabular}{|c|c|c|c|}
\hline & $N$ & $\%$ & \\
\hline Psychosis and on depot neuroleptics & 76 & $55.1^{*}$ & \\
\hline On depot neuroleptics & 105 & 37.5 & \\
\hline At least one clinic attendance following admission & 59 & 21.1 & \\
\hline Length of stay by diagnostic group & Mean & SD & Median \\
\hline Bipolar mood disorder & 34.3 & 50.1 & 21.0 \\
\hline Major depression & 28.7 & 21.5 & 21.5 \\
\hline Other psychotic disorder & 34.8 & 31.3 & 22.0 \\
\hline Parasuicide & 4.5 & 2.1 & 4.5 \\
\hline All other diagnoses & 21.4 & 22.4 & 15.0 \\
\hline Schizophrenia & 48.8 & 65.5 & 31.0 \\
\hline All diagnoses & 36.9 & 51.7 & 24.0 \\
\hline \multicolumn{4}{|l|}{ Time of follow-up for non-readmitted patients (days) } \\
\hline$<31$ & 11 & 6.1 & \\
\hline $31-60$ & 8 & 4.4 & \\
\hline $121-240$ & 22 & 12.2 & \\
\hline$>240$ & 129 & 71.7 & \\
\hline \multicolumn{4}{|l|}{$\begin{array}{l}\text { Time until readmission for those } \\
\text { readmitted (days) }\end{array}$} \\
\hline$<31$ & 25 & 24.5 & \\
\hline $31-60$ & 18 & 17.6 & \\
\hline $61-120$ & 22 & 21.6 & \\
\hline $121-240$ & 18 & 17.6 & \\
\hline$>240$ & 19 & 18.6 & \\
\hline * Percentage of psychotic patients on depot neuroleptics. & & & \\
\hline
\end{tabular}

explanatory power of the model was poor. Model 2 (in Table III) shows results for the full proportional hazards model with a timedependent covariant. The time-dependent covariate was interacted with all independent variables, but since only the visits ratio interaction term was statistically significant, model 2 only includes this higher order effect. The positive sign on the time covariate $x$ visit ratio combined with the negative, but non-significant sign on the visits ratio coefficient indicates a slight initial protective effect of clinic visits against readmission. This wanes over time, however, and for those who have been out of hospital for a long period, clinic visits are associated with a higher risk of readmission.

Models 3 and 4 (in Table III) were estimated with the same set of starting variables as models 1 and 2 respectively, but a stepwise variable selection routine was used to formulate the most parsimonious models.

In model 3, age categories were a significant predictor of risk of readmission, age 40 - 50 years having an apparent protective effect. This was only statistically significant for that group, however, and age categories were not rank ordered in terms of risk of readmission. In addition, being married or partnered appeared to have a significant protective effect against readmission. In model 4 , the time covariate $\times$ visit ratio was again positive and highly statistically significant, and mar- riage again appeared to have a protective effect.

\section{Discussion}

In general, the patients' characteristics and treatment interventions studied showed poor ability to predict risk of readmission in studied psychiatric patients. The only patient characteristic showing a plausible protective effect was that of marriage/cohabitation versus being single.

This finding is in contrast to findings of many other authors. 12,14,15,20 The ability to maintain a partnership may indicate less severe illness, or it may be that a cohabiting partnership in this community confers a more protective effect by virtue of support and help from extended family structures.

The age effect found in model 3 requires further investigation, especially given the lack of rank ordering among the categories.

It appears that clinic attendance confers a small protective effect early after discharge. However, this effect diminishes rapidly and in fact reverses later after discharge. This may be because those who have left the area under study will have no clinic visits and no readmission in the study hospitals, thus falsely associating clinic attendance with higher risk of hospital readmission. Alternatively 
patients who are healthy and not at risk of readmission may themselves choose not to attend a clinic since they have no need for treatment. Several investigators $9,21,22$ have found high levels of attendance at community aftercare facilities to be either inconse- quential or even positively predictive of readmission. This was interpreted as reflecting a pattern whereby the more disturbed patients were more likely to remain in treatment and also to be rehospitalised

\begin{tabular}{|c|c|c|c|c|c|c|}
\hline \multirow{2}{*}{$\begin{array}{l}\text { Model 1. Lower order terms only } \\
\mathrm{N}\end{array}$} & & \multicolumn{5}{|c|}{ Model 2. Independent variables plus time-dependent covariate } \\
\hline & 269 & & & & 269 & \\
\hline-2 log likelihood & 1031 & & & & 1024 & \\
\hline Overall chi-square (DF) & $29.2(23)$ & & & & $39.2(24)$ & \\
\hline Overall model $P$ & 0.17 & & & & 0.024 & \\
\hline Variable & B & SE & $P$ & $B$ & SE & $P$ \\
\hline On depot neuroleptics & 0.0182 & 0.2492 & 0.9417 & 0.0158 & 0.2498 & 0.9495 \\
\hline Female sex & 0.012 & 0.2744 & 0.9651 & 0.0027 & 0.2779 & 0.9924 \\
\hline Age category (yrs) & & & 0.2077 & & & 0.1727 \\
\hline$<21^{*}$ & -0.0684 & 0.4972 & 0.8906 & -0.0467 & 0.5012 & 0.9257 \\
\hline $21-30 *$ & -0.4588 & 0.4275 & 0.2832 & -0.4335 & 0.433 & 0.3168 \\
\hline $31-40^{*}$ & -0.0733 & 0.3937 & 0.8523 & -0.0321 & 0.3971 & 0.9357 \\
\hline $41-50^{*}$ & -0.859 & 0.5079 & 0.0908 & -0.8765 & 0.5098 & 0.0856 \\
\hline Diagnosis & & & 0.1417 & & & 0.1107 \\
\hline Bipolar mood disordert & 0.2278 & 0.291 & 0.4337 & 0.1891 & 0.2963 & 0.5233 \\
\hline Major depression ${ }^{\dagger}$ & 0.0144 & 0.4632 & 0.9753 & -0.0102 & 0.4654 & 0.9825 \\
\hline Other psychosis ${ }^{\dagger}$ & -0.4562 & 0.4282 & 0.2867 & -0.569 & 0.4334 & 0.1892 \\
\hline Parasuicide ${ }^{\dagger}$ & -1.7107 & 1.0568 & 0.1055 & -1.8532 & 1.0669 & 0.0824 \\
\hline All other diagnoses ${ }^{\dagger}$ & -0.6619 & 0.4156 & 0.1112 & -0.6808 & 0.4161 & 0.1018 \\
\hline Educational level & & & 0.9756 & & & 0.9592 \\
\hline Less than Std $8 \ddagger$ & -0.0505 & 0.7559 & 0.9467 & -0.1071 & 0.7605 & 0.888 \\
\hline Std 8 or $9 \ddagger$ & 0.0354 & 0.7671 & 0.9632 & 0.0126 & 0.7705 & 0.9869 \\
\hline Std $10 \ddagger$ & -0.1812 & 0.9077 & 0.8418 & -0.1988 & 0.9101 & 0.8271 \\
\hline Employed & -0.2009 & 0.3928 & 0.609 & -0.1724 & 0.3946 & 0.6623 \\
\hline Married/partnered & -0.4687 & 0.2938 & 0.1106 & -0.4841 & 0.2946 & 0.1004 \\
\hline Substance abuse & -0.2325 & 0.2669 & 0.3836 & -0.2455 & 0.2693 & 0.362 \\
\hline Violent behaviour & 0.1309 & 0.2655 & 0.6219 & 0.1747 & 0.2686 & 0.5153 \\
\hline Visits ratio & 0.4738 & 0.3026 & 0.1175 & -0.4154 & 0.4889 & 0.3955 \\
\hline Discharge date & & & 0.8418 & & & 0.8428 \\
\hline First quarter $\S$ & -0.1523 & 0.4109 & 0.7109 & -0.1713 & 0.4133 & 0.6785 \\
\hline Second quarter§ & -0.0421 & 0.3642 & 0.9079 & -0.0647 & 0.3662 & 0.8597 \\
\hline Third quarter§ & -0.2567 & 0.3903 & 0.5107 & -0.2719 & 0.3922 & 0.4881 \\
\hline Length of hospital stay & 0.00050 & 0.0026 & 0.8378 & 0.00069 & 0.0026 & 0.7925 \\
\hline \multirow[t]{2}{*}{ Time covariate $x$ visit ratio } & & & & 0.241 & 0.0881 & 0.0062 \\
\hline & Model 3 & & & & Model 4 & \\
\hline-2 log likelihood & 1045 & & & & 1047 & \\
\hline Overall chi-square (DF) & $16.7(5)$ & & & & 19.17 & \\
\hline Overall model P & 0.005 & & & & 0.001 & \\
\hline Variable & $B$ & SE & $P$ & $B$ & SE & $P$ \\
\hline Age category (yrs) & & & 0.048 & & & \\
\hline$<21^{*}$ & -0.524 & 0.437 & 0.231 & & & \\
\hline $21-30 *$ & -0.65 & 0.364 & 0.072 & & & \\
\hline $31-40^{*}$ & -0.133 & 0.353 & 0.706 & & & \\
\hline $41-50 *$ & -1.004 & 0.476 & 0.035 & & & \\
\hline Married/partnered & -0.654 & 0.269 & 0.015 & -0.652 & 0.267 & 0.015 \\
\hline Time covariate $\mathrm{x}$ visit ratio & & & & 0.177 & 0.052 & 0.001 \\
\hline $\begin{array}{l}\text { * Compared with over-50 group. } \\
\text { † Compared with schizophrenic group. } \\
\text { † Compared with those with post-school qualifications. } \\
\text { \& Compared with fourth quarter. } \\
B=\text { coefficient; } S E=\text { standard error. }\end{array}$ & & & & & & \\
\hline
\end{tabular}


Solomon et al. ${ }^{20}$ however, refined this discussion with their finding that the specificity of outpatient services related to the individual patient's needs was a potent predictor of readmission. They argue against the use of crude clinic attendance as a proxy of quality of aftercare services.

It should be noted that very few patients attended community clinics at all (21\%), and such low compliance rates make it difficult to evaluate the contribution of community care.

\section{Length of hospital stay}

Failure to show a correlation between short length of stay and likelihood of readmission was in line with findings of some authors, ${ }^{16,17,23}$ and contradicted findings of others. ${ }^{14,15,24}$ The positive interpretation is that patients are being given adequate attention for the severity of their illness and that patients are being admitted for the duration they require, despite the pressure on bed occupancy.

Severity of illness and particularly instability close to discharge have been noted as important predictors of readmission. ${ }^{11,23,25}$ This may therefore obscure the relationship between length of stay and readmission, although Mojtabai et al., ${ }^{10}$ controlling for symptom severity on discharge, still showed a protective effect for shorter length of admission.

\section{Depot neuroleptics}

While it has been shown that depot neuroleptics reduce hospitalisation ${ }^{26}$ and the direct costs of schizophrenia, ${ }^{27}$ this study showed no protective effect even in the first 30 days post discharge. The absence of a protective effect was very likely due to the lack of randomisation and the likelihood that the most severely ill patients received depot medication. It would be useful in the future to focus on the effect of a pre-discharge depot neuroleptic on the post-discharge period in a randomised and prospective way.

Mojtabai et al. ${ }^{10}$ incorporated interactions between independent variables in their model, and produced some significant results. Testing for multiple interaction effects was not possible here because of the small sample size. Specific statistical interactions with the 'marital status' term were tested, however, because of the findings of Mojtabai et al. ${ }^{10}$ and our own model (not reported in the results). The protective effect of the partnered/married variable was significantly enhanced by employment and use of depot neuroleptics, and diminished by the presence of violent behaviour. However, these findings did not materially affect the conclusions of the study.
It is notable that the hazard of readmission is not fixed and that the period of 90 days post discharge constitutes a high-risk period despite hospital-based interventions. The hospital appears to serve an asylum function (keeping patients and community safe), but does not necessarily make an impact on the patient's ability to remain in the community.

The major limitation of the study was the small sample size. Record reviews limited diagnostic accuracy, but this was partially compensated for by the fact that many of the patients were well known to two members of the team (GMB and CC). The reliance on record reviews also limited our ability to track patients accurately and denominator loss may have been significant. Finally, the strict criteria used for recording substance abuse and violence may have masked the contribution of these factors.

The difficulty in identifying readmission risk variables in a consistent way is confirmed in this study. However, significant gains in relapse prevention have been demonstrated by specific aftercare interventions, ${ }^{2831}$ which are notably absent in our setting. It may be that the most important effect of these interventions is in stabilising the post-discharge period and that in societies with limited resources such as ours, intensive management of patients for the acute period of 3 months after discharge would yield significant gains.

The authors would like to thank Ms Ankie Nteo for help in retrieving records. We also thank our colleagues at the Chris Hani Baragwanath Hospital for their help and advice.

\section{References}

1. Appelby L, Luchins DJ, Desai PN, et al. Leng h of inpatient stay and recidivism among patients wih schizophrenia. Psychiatric Services 1996; 47: 985-990.

2. Kastrup M. Who became revolving door patients? Acta Psychiatr Scand 1987; 76: 80-88.

3. Lewis T, Joyce PR. The new revolving door patients: results from a national cohort of first admissions. Acta Psychiatr Scand 1990; 82: 130-135.

4. Colenda CC, Hamer RM. First admission young adult patients to a state hospital: relative risk for readmission. Psychiatr Q 1989; 60: 227-235.

5. Casper ES, Donaldson B. Subgroups in the population of frequent users of inpatient services. Hospital and Community Psychiatry 1990; 41 : 189-191.

6. Tansella M, Micciolo R, Biggeri A, et al. Episodes of care for first-ever psychiatric patients. A long term case-register evaluation in a mainly urban area. Br J Psychiatry 1995; 167: 220227.

7. Stickney SK, Hall RCW, Gardner ER. The effect of aftercare referral procedures on aftercare compliance. Hospital and Community Psychiatry 1980; 31: 567-569.

8. Kastrup $M$. The use of a psychiatric register in predicting the outcome "revolving door patient". Acta Psychiatr Scand 1987; 76: 552-560

9. Sullivan $G$, Wells KB, Morgenstern $\mathrm{H}$, et al. Identifying modifiable risk factors for rehospitalisation. A case-control study of seriously mentally ill persons in Mississippi. Am J Psychiatry 1995; 152: 1749-1755.

10. Mojtabai R, Nicholson RA, Neesmith DH. Factors affecting relapse in patients discharged from a public hospital: Results from survival analysis. Psychiatr Q 1997; 68: 117-128.

11. Postrado LT, Lehman AF. Quality of life and clinical predictors of rehospitalisation of persons wi h severe mental illness. Psychiatric Services 1995: 46: $1161-1165$.

12. Vogel S, Huguelet P. Factors associated with multiple admissions to a public psychiatric hospital. Acta Psychiatr Scand 1997; 95: 244-253. 
13. Green JH. Frequent rehospitalisation and noncompliance with treatment. Hospital and Community Psychiatry 1988; 39: 963-965.

14. Appelby L, Desai PN, Luchins DJ, et al. Length of stay and recidivism in schizophrenia: a study of public psychiatric hospital patients. Am J Psychiatry 1993; 150: $72-76$

15. Mortenson PB, Eaton WW. Predictors for readmission risk in schizophrenia. Psychol Med 1994; 24: 223-232.

16. Lyons IS, O' Mahoney MT, Miller SI, et al. Predicting readmission to the psychiatric hospital in a managed care environment: implications for quality indicators. Am J Psychiatry 1997 154: $337-340$

17. Goodpastor WA, Hare BK. Factors associated w th multiple readmissions to an urban public psychiatric hospital. Hospital and Community Psychiatry 1991; 42: 85-87.

18. American Psychiatric Association. DSMIV: Diagnostic and Statistical Manual of Mental Disorders. Washington, DC: APA, 1-886

19. Cox DR, Oakes D. Analysis of Survival Data. London: Chapman \& Hall, 1984

20. Solomon P, Gordon B, Davis J. Differentiating psychiatric readmissions from nonreadmissions Am J Orthopsychiatry 1984; 54: 426-434

21. Neuring E, Thayer J, Lander R. On the factors predicting rehospitalisation among two state mental hospital patient populations. Admin Ment Health 1980; 7: 247-270

22. Swett $C$. Syndrome severity and number of previous psychiatric admissions as predictors of readmission. Psychiatric Services 1995; 46: 482-485

23. De Francisco $D$, Anderson $D$, Pantano $R$, et al. The relationship between length of hospital stay and rapid readmission rates. Hospital and Community Psychiatry 1980; 31: 196-197.

24. Davis JM, Metalon L, Watanabe MD, et al. Depot antipsychotic drugs. Place in therapy.
Drugs 1994; 47: $741-773$

25. Monnelly EP. Instability before discharge and previous psychiatric admissions as predictors of early readmission. Psychiatric Services 1997; 48: 1548-1586.

26. Glazer WM. Ereshefsky L. A pharmacoeconomic model of outpatient antipsychotic therapy in "revolving door" schizophrenic patients. J Clin Psychiatry 1996; 57: 337-345.

27. Gillis $L S$, Koch $A$, Joyi $M$. The value and cost effectiveness of a home-visiting programme for psychiatric patients. S Afr Med J 1990; 77: 309-310.

28. Mellsop GW, Blair-West GW, Duraiappah V. The effect of a new integrated mental hea th service on hospitalisation. Aust N ZJ Psychiatry 1997; 31: 480-483.

29. Santos $A B$, Hawkins $G D$, Julius $B$, et al. A pilot study of assertive community treatment for patients w h chronic psychotic disorders. Am J Psychiatry 1993; 150: 501-504

30. McGrew JH, Bond GR, Dietzen $L$, et al. A multisite study of client outcomes in assertive community treatment. Psychiatric Services 1995; 46: 696-701.

31. Quinlivan R, Hough R, Crowell A, et al. Service utilisation and costs of care for severely mentally ill clients in an intensive case management program. Psychiatric Services 1995; 46: $365-371$

Reprinted from the South African Medical Journal (2002; 92: 369-374).

\section{Cross-Cultural Psychiatry}

\section{A Practical Guide}

\section{Dinesh Bhugaand Kamaideep Biki}

Revieus

The authors are to be oongratulated in managing to condense such a complex and changing subject into a brief guide which I thirk should be available in the library of enery prolessicnal and secondary mental health care, and be availatle as a resource in primary mental haalth care." Phinary Care Asychiatty

A practical quida to managing the mental health care of patients from different cultures.

Within cur increasingly multi-cultural sociaty, the needs of patients from other cultures, especialy the minonity ethric groups, are being reocgnized at local and national bvels. Cross-cultural Psychiatry shows in delail how to aclapt Iracitional dirical practice for the cross-cultural client." Key Features:

- Thecretical background to cross-cultural issuas presented in an accessitle way

- Case ilustrations from actual practios highight the main issues and pitfalls

- Focuses cn cinical issues and skils

- Written by acknowledged experts in the field of transcultural psychiatry.

Dec 2000, paperback, 160 pp. $234 \times 156 \mathrm{~mm}$. R325

\section{Adolescent Psychiatry in} Clinical Practice

Edited by Simon G. Gowers

Adolescent psychialry is a poorly undarstood field which requires specialistknowkdge to imcrove understanding and management of the problems facedby this group. In this practical bcok specialist professiznals offer comprehensive and authoritalive coverage of the curent approaches b practice in addescent psychialry. They review a broad range of disorclers and evaluat the treatments and services used. Muchnew information is presented in a highly readable manner. The general peychiatrist wil benefit from the authors expertise, and can easily incorporate their recommendations into their osn work with adolescents.

Key Features:

- Proides a foundation tor understanding adzlescents and their developments

- Addresses the many psychiatric disorders ol adolescents and ther bestmanagement

- Informaticn is easily aqplied bo day-to-day cliricaluse

- Givesguidance on dirical management and planring the development of services.

Feb 2001, papertack, 576 pp, 234 x $156 \mathrm{~mm}$, R899

\section{ORDERS}

SA Medical Asscciation, Private Bag X1. Pinelands 7430. Tel (021) 530-6527. Fax (021) 531-4126.

E-mail: fpalm@ samedical.org. Limited local stock. 